\title{
Currículo, cultura e formação de professores ${ }^{*}$
}

Antonio Flavio Barbosa Moreira **

\begin{abstract}
RESUMO
O artigo apresenta reflexões sobre currículo e formação de professores, situando-as no contexto de um mundo multicultural dominado pela lógica neoliberal. Discute em que medida os atuais currículos dos cursos de formação de professores estão formando profissionais capazes de atuar como intelectuais questionadores do existente, multiculturalmente orientados e preocupados em pesquisar e aprimorar suas próprias práticas. Revê, então, a concepção do professor como intelectual transformador e como profissional reflexivo, defendendo que na formação docente se levem em consideração as diferentes dimensões da prática pedagógica.

Palavras-chave: currículo, formação de professores, multiculturalismo.
\end{abstract}

\begin{abstract}
This paper offers a reflection on curricula and teacher's formation, placing it in a multicultural world which is ruled by neoliberal logic. Present curricula are discussed and they way they might influence teacher's formation as intellectuals capable of questioning what is presently multiculturally presented and concerned about research and how to make their own practices even better developed. It reviews the teacher's concept as an intellectual who can accept changes and as a professional who is capable of reflections, supporting teaching formation and different dimensions of pedagogical practice.
\end{abstract}

Key-words: curriculum, teacher's formation, multiculturalism.

* Trabalho apresentado no Congresso Íbero-Americano - Santa Maria - RGS - 19 de abril de 2000.

** Professor Titular da Faculdade de Educação da UFRJ - Doutor em Educação pela Universidade de Londres. afmcju@infolink.com.br 


\section{Introdução}

Parto do pressuposto de que as reflexões sobre currículo devem incluir, necessariamente, reflexões sobre o professorado e sobre sua prática. Se a concepção de currículo corresponde às experiências pedagógicas em que docentes e estudantes constroem e reconstroem conhecimentos, se cabe aos docentes participação ativa no processo de planejar e desenvolver tais experiências, não ocorre desenvolvimento curricular se não ocorrer simultaneamente o desenvolvimento do professor e, com ele, o aperfeiçoamento das práticas escolares (ALVAREZ MÉNDEZ, 1990). Logo, não se pode pensar currículo sem se pensar o professor e a sua formação.

Trata-se hoje de pensar o currículo e de pensar o professor em tempo de hegemonia do neoliberalismo. Conforme se tem argumentado em inúmeras análises, é ao modelo neoliberal que se pode atribuir, em grande parte, o incremento dos contrastes tanto no interior dos países de Primeiro e Terceiro Mundo como entre eles; o aumento do desemprego, que chega a atingir, na América Latina, cerca de 9,5\% da força de trabalho, e que penaliza, dominantemente, mulheres e jovens; a consolidação do modelo da sociedade de consumo, que permite a poucos privilegiados o acesso aos mais sofisticados bens de consumo; assim como o lamentável desenvolvimento de valores pautados no lucro e no individualismo. É ao neoliberalismo, em síntese, que se deve associar tanto a intensificação das dificuldades econômicas enfrentadas pela maioria da população do globo terrestre como o desaparecimento progressivo de universos mais autônomos de produção cultural. Segundo BOURDIEU (1998a), a destruição das bases econômicas e sociais das aquisições culturais da humanidade, que se verifica nas sociedades neoliberais contemporâneas, tem, crescentemente, subordinado a esfera cultural aos interesses comerciais, empresariais, burocráticos ou estatais dominantes, tornando-a cada vez mais dependente desses mesmos interesses.

Difícil de ser questionado, o neoliberalismo se apresenta, arrogantemente, como descrição científica do mundo real, como teoria pura, como corpo de doutrina coerente e consistente, como a única saída, como a única solução técnica possível. Transforma-se, de fato, no senso comum de uma época. Nesse sombrio contexto, BOURDIEU (1998b) propõe a reconquista da democracia e insiste em que se preserve a esperança, a seu ver possível pela ação de indivíduos e grupos que ainda insistem em construir uma ordem social que não se paute pela busca do interesse egoísta ou pela paixão individual pelo lucro. 
Trata-se, também, de pensar currículo e formação de professores em uma sociedade cada vez mais multicultural, em uma sociedade em que a pluralidade de culturas, etnias, religiões, visões de mundo e outras dimensões das identidades infiltra-se, cada vez mais, nos diversos campos da vida contemporânea. A complexidade das relações, tensões e conflitos resultados dos choques entre essas identidades plurais e de suas lutas por afirmação e representação em políticas e práticas sociais extrapola o âmbito da investigação e da reflexão que se desenvolve nas universidades. Esse tenso panorama invade o cotidiano, evidencia-se nos noticiários repletos de preconceitos, xenofobia, violência e guerras, nos espaços virtuais, em que crescentemente se veiculam mensagens racistas e discriminatórias, bem como em qualquer espaço em que se mostra a face desumana do ódio, da agressão, da exclusão ou do desprezo ao "outro", percebido e tratado como diferente (CANEN; MOREIRA, 1999).

Considerar o caráter multicultural da sociedade no âmbito do currículo e da formação docente implica respeitar, valorizar, incorporar e desafiar as identidades plurais em políticas e práticas curriculares. Implica, ainda, refletir sobre mecanismos discriminatórios ou silenciadores da pluralidade cultural, que tanto negam voz a diferentes identidades culturais, silenciando manifestações e conflitos culturais, como buscam homogeneizá-las em conformidade com uma perspectiva monocultural. Tais reflexões, tão propagadas e ao mesmo tempo tão criticadas, têm informado o que se considera uma prática pedagógica multiculturalmente orientada, oposta às intenções de homogeneização, competitividade e produtividade que norteiam as políticas educacionais liberais.

É, então, no contexto de um mundo reconhecidamente multicultural, mas dominado pela ideologia neoliberal, que procuro situar minha reflexão sobre o currículo, o professor e a sua formação.

\section{Algumas reflexões sobre o currículo}

A literatura especializada tem registrado, ao longo dos tempos, diferentes significados para a palavra currículo. Dominam, dentre eles, os que associam currículo a conteúdos e os que vêem currículo como experiências de aprendizagem. Outras concepções apontam para a idéia de currículo como plano, como objetivos educacionais, como texto e, mais recentemente, como 
quase sinônimo de avaliação. Minha opção é admitir a importância e a necessária articulação dos diferentes elementos enfatizados em cada uma das concepções apresentadas e, ao mesmo tempo, considerar o conhecimento como a matéria prima do currículo, entendendo então currículo como o faz SILVA (1996), como o "conjunto de experiências de conhecimento que a escola oferece aos estudantes."

Tanto os planos como os encontros efetivos que reúnem professores e alunos gravitam em torno do conhecimento. É fundamentalmente pelo conhecimento que se procura atingir as metas definidas para um curso, para uma escola ou para um sistema educacional. A centralidade do conhecimento nas questões e decisões curriculares é plenamente reconhecida pelos autores da teoria curricular crítica, que vêm se empenhando, desde a década de setenta, em compreender as relações entre conhecimento escolar e poder. Apoiando-se principalmente no neo-marxismo de Gramsci e nos pensadores da Escola de Frankfurt, são numerosos os estudos que, focalizando o currículo oficial, o currículo oculto e o currículo em ação, bem como os recursos empregados e as relações sociais estabelecidas na prática curricular, procuram entender como o conhecimento escolar tem contribuído para preservar relações de poder que oprimem determinados grupos e indivíduos e garantem os privilégios de outros.

Durante vinte anos, essa teorização crítica, desenvolvida pelos neos (APPLE, 1996), responde por intensa produção científica. Somente perde parte de seu prestígio no início da década de noventa, quando o pensamento sobre currículo passa a refletir a influência de novos discursos e a evidenciar a preocupação com novas questões. Nos mais recentes estudos, tanto em países como Estados Unidos e Inglaterra, tradicionais no estudo do currículo, como no Brasil, observa-se com clareza o aproveitamento de categorias e o desenvolvimento de temas dos estudos culturais e do pensamento pós-moderno e pós-estrutural, que ou se associam, em uma combinação nem sempre satisfatoriamente resolvida, aos princípios da teoria curricular crítica, ou deles se afastam, diria eu, às vezes precipitada e equivocadamente.

Trava-se, então, um vigoroso embate entre os neos e os pós (APPLE, 1996). A meu ver, embora os riscos envolvidos na aproximação entre as duas tendências não sejam poucos, são inegáveis a riqueza e a originalidade de algumas interpretações que têm caminhado nessa direção. Considero, portanto, ser desejável favorecer as tensões e os atritos entre as duas tradições de modo a propiciar a emergência de novos e frutíferos veios de análises, cuidando-se, ao mesmo tempo, de evitar impasses teóricos ou abandonos apressados. 
Nesse sentido, vejo como bastante produtiva, no pensamento curricular crítico contemporâneo, a linha de análise que, partindo do ponto de vista de que o currículo representa uma seleção da cultura, uma escolha que se faz em um amplo universo de possibilidades, e considerando a cultura como espaço em que significados se produzem, concebe o currículo como uma prática de significação que, expressando-se em meio a conflitos e relações de poder, contribui para a produção de identidades sociais (SILVA, 1999). A partir dessa perspectiva, procura compreender os nexos entre conhecimento escolar, identidade e poder, consolidando e ampliando, desse modo, o foco dos primeiros estudos críticos do campo do currículo.

O currículo é visto como território em que ocorrem disputas culturais, em que se travam lutas entre diferentes significados do indivíduo, do mundo e da sociedade, no processo de formação de identidades. Essa constatação levanta, inevitavelmente, algumas questões. Que identidades os atuais currículos estão ajudando a produzir? Que identidades deveriam produzir? Identidades em sintonia com padrões dominantes ou identidades plurais? Identidades comprometidas com o arranjo social existente ou identidades questionadoras e críticas?

No caso particular da formação de professores cabe indagar: que professores estão sendo formados, por meio dos currículos atuais, tanto na formação inicial como na formação continuada? Que professores deveriam ser formados? Professores sintonizados com os padrões dominantes ou professores abertos tanto à pluralidade cultural da sociedade mais ampla como à pluralidade de identidades presente no contexto específico em que se desenvolve a prática pedagógica? Professores comprometidos com o arranjo social existente ou professores questionadores e críticos? Professores que aceitam o neoliberalismo como a única saída ou que se dispõem tanto a criticá-lo como a oferecer alternativas a ele? Professores capazes de uma ação pedagógica multiculturalmente orientada?

A meu ver, examinar tais questões requer, previamente, que se reflita sobre o professor que se deseja formar. É esse o ponto que abordo a seguir.

\section{O professor como intelectual}

Em estudo anteriormente desenvolvido (MOREIRA, 1995), apoiei-me em GIROUX (1988) para destacar a utilidade de se conceber professores e 
professoras como intelectuais. Em primeiro lugar, a categoria permite que se repense o trabalho docente, oferecendo a base teórica necessária para considerar o trabalho docente como intelectual e não apenas técnico. Em segundo lugar, a categoria é útil na medida em que procura definir as condições necessárias para que o professor funcione como intelectual. Em terceiro lugar, a categoria sugere ao professor lutar pela concretização dessas condições. Por fim, ajuda a iluminar o papel que o professor, por meio de sua prática, desempenha na produção e na legitimação de determinados interesses.

Na década de oitenta, GIROUX (1988) sustenta que o professor precisa atuar como intelectual transformador, fundamentando suas atividades em um discurso moral e ético pautado na preocupação com o sofrimento e a luta dos oprimidos. Essa visão de intelectual aponta para um profissional capaz de articular e desenvolver possibilidades emancipatórias em espaços mais específicos. $\mathrm{O}$ autor acrescenta que esse profissional: (a) procura explicitar os fundamentos de uma pedagogia crítica, explicitando sua relevância para os estudantes e para os demais membros da sociedade; (b) esforça-se por tornar o pedagógico mais político e o político mais pedagógico; (c) busca unir a linguagem da crítica à linguagem da possibilidade; e (d) concebe as salas de aula como espaços nos quais podem ser projetadas as condições necessárias ao desenvolvimento de novas formas culturais, novas práticas sociais, novos modos de comunicação e situações materiais mais satisfatórias (MOREIRA, 1995).

Novas influências - do pensamento pós-moderno e dos estudos culturais - levam GIROUX (1988) a reelaborar sua concepção do professor como intelectual, optando por substituir, nos anos noventa, o termo transformador. $\mathrm{O}$ autor questiona a visão de intelectual como um indivíduo iluminado, capaz de conscientizar as massas e de definir, a priori, os rumos do processo de mudança. Propõe o intelectual público, voltado para ampliar os espaços públicos em que discussões e decisões possam ocorrer, assim como para combinar concepção e implementação, pensamento e prática, com o projeto coletivo de uma cultura pautada por liberação e por justiça. Na visão de intelectual público associam-se, ao caráter político da prática docente, bastante acentuado na figura do intelectual transformador, a preocupação com o caráter discursivo dessa prática, a valorização da esfera cultural e a crença na importância do debate público. Destaca-se o foco pós-moderno e pós-estrutural no discurso, entendido como uma prática que contribui para construir a realidade à qual se refere.

Segundo GIROUX e ARONOWITZ (1991), o professor precisa examinar a relação entre conhecimento, aprendizagem e poder, entendendo-a como parte de um discurso político a ser reconstruído e colocado a serviço da liber- 
dade humana. Precisa levar o aluno a compreender como conhecimento e poder se associam na leitura e na elaboração de textos, o que significa tanto analisar como as relações de poder se manifestam nos textos como comprometer-se com a luta concreta por condições mais dignas e justas de vida. Como intelectual público, o professor deve reconhecer o caráter parcial dos discursos, questionar as especificidades dos pontos de vista, afrontar os critérios de uma verdade supostamente universal, abrindo-se, ao mesmo tempo, ao diálogo, a um projeto mais amplo de construção da solidariedade e de uma sociedade democrática. Daí a importância de uma linguagem da imaginação, de uma linguagem de possibilidades não realizadas. (MOREIRA, 1998).

Apóio-me em SARLO (1999) para destacar outro ponto que me parece central hoje na visão do professor como intelectual. Para enfrentar os problemas que encontra no cenário cultural argentino, SARLO (1999) propõe saídas a partir de perguntas que favoreçam o ver, em vez de perguntas que pretendam ajudar a encontrar, imediatamente, guias para a ação. Nesse sentido, perguntas referentes a como alcançar uma perspectiva para ver são mais desejáveis que perguntas referentes ao que fazer. Em conformidade com esse ponto de vista, define a atividade intelectual "pelo questionamento do que parece inscrito na natureza das coisas, questionamento esse cuja intenção é fundamentalmente mostrar que as coisas não são inevitáveis”. Em outras palavras, propõe que o intelectual envide esforços no sentido de tornar evidente que muito do que é visto como natural, assim o é por atender à manutenção de privilégios e interesses de determinados grupos. A "desnaturalização" de aspectos que costumam oprimir indivíduos e grupos constitui, por conseguinte, forma pela qual o intelectual expressa seu compromisso político.

Com SAID (1996), vejo o intelectual como um sujeito com um papel específico na sociedade, que não se restringe à competente atuação em uma dada categoria profissional. O intelectual "é um indivíduo dotado da faculdade de representar, encarnar e articular uma mensagem, uma visão, uma atitude, filosofia ou opinião para e a favor de um público" (SAID, 1996, p. 29-30). O intelectual é um indivíduo cujo maior objetivo é fazer progredir a liberdade e o conhecimento. Para cumpri-lo, acrescento, o intelectual não pode abdicar de sua autonomia, de sua integridade, de sua ética, de sua crítica. Não pode aceitar que as coisas continuem a ser inexoravelmente como são, não pode deixar-se cooptar e terminar referendando discursos autoritários que discriminam, que desprezam as necessidades humanas, que desvalorizam o social e o cultural.

Baseando-me mais uma vez em SARLO (1999), penso que as perguntas "Essa atitude é justa? Quem com ela se beneficia além de mim?" precisam 
ser feitas e debatidas em uma sociedade solidária e democrática. Suas respostas certamente não garantem justiça social. Todavia,

em um mundo crescentemente homogêneo e crescentemente individualista (uma combinação fatal de qualidades), pelo menos permite assumir o ponto de vista do outro. Essa seria a consequiência pluralista de considerar questões gerais. Sem uma perspectiva geral o pluralismo não é tolerante, mas sim particularismo. Perguntas que exigem uma discussão sobre a igualdade e a justiça constituem o limite intelectual a ser posto aos desenvolvimentos sociais que induzem a uma ação desconectada de uma perspectiva de bem comum. (SARLO, 1999, p. 191)

O que se defende é a necessidade de se buscar o consenso em relação a um projeto coletivo de transformação do existente. Para isso, empatia e solidariedade podem ser úteis. São elas que incitam o respeito a diferentes pontos de vista e, ao mesmo tempo, induzem ao reconhecimento de que as interrelações entre os distintos grupos devem fazer com que cada um se responsabilize parcialmente pelo outro (WELCH, citada por MCLAREN, 1993).

SARLO (1999) afirma, ainda, que uma cultura precisa estar em condições de nomear as diferenças que a integram. Se não o fizer, a liberdade cultural restringe-se a um exercício destinado a realizar-se unicamente nos espaços das elites estéticas e intelectuais. É indispensável, argumenta, uma crítica cultural que denuncie estratégias elitistas e neopopulistas que inviabilizam o projeto de construção de uma sociedade mais solidária e democrática. Daí a importância de um professor que, bem desempenhando seu papel de intelectual, procure tanto denunciar e desnaturalizar fatores opressivos e relações de poder assimétricas, como contribuir para o anúncio de alternativas que caminhem na contra-mão de visões e interesses hegemônicos.

Ponto de vista similar é encontrado em considerações de YOUNG (1995), referentes à educação. Segundo ele, o panorama educacional contemporâneo inclui macro e microproblemas que, embora entrelaçados, precisam ser distinguidos. O primeiro refere-se à diferença, aos problemas das minorias, claramente identificáveis nas escolas e salas de aula. O segundo é o problema da crítica, que se manifesta como um problema de diálogo, de interpretação e de uma praxis relativamente autônoma de intelectuais e profissionais, inclusive professores e alunos. O autor coloca-se, então, a favor de se promover a tensão entre poder e liberdade, entre a celebração da diversidade específica e a 
atuação política em prol de mudanças mais amplas nas organizações sociais e na ideologia. Ou seja, além de micropolíticas situadas, locais, vê como indispensáveis estratégias políticas abrangentes. Nesse sentido, o pensamento crítico, se não representa uma solução para os macroproblemas a serem enfrentados, pode iluminar relações e pontos antes não percebidos e sugerir caminhos antes não vislumbrados.

No mesmo estudo a que já me referi (MOREIRA, 1995), argumentei ser indispensável acrescentar ao caráter político presente na visão de GIROUX (1988) o caráter acadêmico, expresso no compromisso com a busca da verdade, com a investigação e com o estudo, que precisa caracterizar a prática docente. Revejo meu ponto de vista e o formulo hoje da seguinte forma: tanto a prática profissional como o preparo do professorado precisam combinar dimensões de ordem política, cultural e acadêmica. Essa perspectiva instiga o professor a assumir-se como intelectual, de modo a evidenciar: o compromisso com lutas particulares, no contexto em que atua, e, ao mesmo tempo, com a construção de uma sociedade menos opressiva; o permanente propósito de mostrar, por meio da crítica cultural, que as coisas não são inevitáveis; a preocupação em fazer avançar o conhecimento e a liberdade; bem como o empenho em auto-aperfeiçoar-se e aperfeiçoar sua prática. Ainda que outras dimensões também se devam fazer presentes no delineamento da identidade docente, como a ética e a estética, deixo, conscientemente, de abordá-las neste texto, visando priorizar as que acabo de mencionar.

Examino, a seguir, se e como a idéia do professor pesquisador de sua prática pode de fato ser útil para incrementar o aspecto acadêmico que julgo dever integrar o trabalho e a formação docente.

\section{O professor como pesquisador-em-ação}

Com base na visão de profissional reflexivo de SCHÖN (1982), tem-se estimulado o professor a pesquisar sua própria prática. Tendo em mente que inúmeros têm sido os argumentos em defesa desse ponto de vista e que já se tem, em muitos casos, buscado materializar as sugestões derivadas da literatura que o aborda, eximo-me de caracterizá-lo e de destacar suas propaladas contribuições. Contudo, inspiro-me em POPKEWITZ (1995), que discute a importância atribuída ao professor reflexivo em inúmeras reformas educacionais contemporâneas, para seguir outra linha de análise. 
Tais reformas ressaltam disposições e sensibilidades que tornem os docentes auto-realizados, auto-motivados e auto-dirigidos. "Está-se diante de novos padrões de auto-regulação, comparáveis aos que se encontram na organização pós-fordista do trabalho" (POPKEWITZ, 1995). A produção em massa hierarquicamente ordenada, que buscava tornar o trabalhador competente em tarefas específicas de uma linha de montagem, perdeu sua eficiência. O princípio das novas organizações é hoje a lei do microcosmo, segundo a qual estruturas mais ágeis e flexíveis envolvem grupos de trabalhadores participantes de determinados projetos e não subordinados à forma tradicional de gerenciamento. Essas unidades menores são desenvolvidas, por trabalhadores mais poderosos, em ambientes mais flexíveis e passíveis de se modificarem em consonância com novas demandas.

Nesse contexto, a atividade produtiva deixa de configurar processo no qual o indivíduo se define pelo trabalho que desempenha, para corresponder a um espaço de promoção de suas habilidades pessoais. O trabalhador é visto, então, como membro eficiente de uma equipe, como capaz de bem enfrentar dificuldades que surjam no decorrer de sua prática. POPKEWITZ (1995) o associa ao professor reflexivo, cujas capacidades e habilidades devem também relacionar-se pragmaticamente ao local de trabalho. Num caso e noutro, querse desenvolver disposições flexíveis, não mais competências isoladas. Daí a exigência de características como auto-confiança, auto-disciplina, habilidade para identificar e resolver problemas, capacidade e vontade de aprender.

Pesquisar a própria prática revela-se, pois, mais que simples estratégia para assegurar competência: implica, de fato, mudança na forma de controle político do professorado. Constitui processo de regulação que ocorre por meio de categorias que constroem um dado tipo de pessoa e de profissional. Visa a produzir certos modos de ver, pensar, agir e falar sobre si próprio, sobre os indivíduos e sobre o mundo. Em outras palavras, a preocupação em incentivar os docentes a se tornarem professores reflexivos não é inócua, mas expressa, mesmo, a intenção de fazer o professorado funcionar, controlar-se e ver-se de uma determinada maneira, certamente em harmonia com a atual organização do trabalho e dos sistemas educacionais nas sociedades contemporâneas. Parece, então, que a proposta que se pretendeu empregar para garantir maior reflexão, autonomia e qualidade no trabalho docente acabou sendo incorporada, com propósitos mais conservadores, nos discursos oficiais proferidos por autoridades de inúmeros países.

Essa estratégia, aliás, já é bastante conhecida: tem sido sobejamente empregada por governos neoliberais contemporâneos, mestres em se apoderar com eficiência de idéias defendidas por setores progressistas, em 
recontextualizá-las, em distorcê-las e em fazê-las funcionar a favor de outros interesses. Exemplifico com a presença, em recentes textos elaborados por nossos governantes, de preocupações com: educação para a cidadania, educação para a democracia, valorização da escola fundamental, qualidade no ensino, avaliação da escola e da universidade públicas, educação multicultural etc. No contexto em que vêm sendo empregados, tais termos tendem a assumir conotações mais ligadas à eficiência e à produtividade que ao fortalecimento do poder dos alunos das camadas populares.

Conforme argumenta MENDES (1990, p. 90),

Quando o poder se apropria da linguagem progressista e de vanguarda, as palavras se perdem ou se fossilizam no jargão burocráticoadministrativo e deixam de ter seu sentido original, criador e emancipador, desvirtuam-se, esvaziam-se semanticamente ou adquirem valores polissêmicos.

Cabe, então, perguntar: há que se abandonar a idéia do professor reflexivo? Vale pretender associá-la à idéia do professor intelectual, do professor culturalmente orientado? Quero argumentar que em ZEICHNER (1993) encontram-se pistas para possíveis saídas, ou seja, para se preservar a idéia e neutralizar alguns dos perigos denunciados por POPKEWITZ (1995). Amparando-me então em ZEICHNER (1993), sugiro que no desenvolvimento da prática reflexiva: (a) nos voltemos tanto para dentro, para a prática, como para fora, para as condições sociais e culturais em que a prática se desenvolve e contribui para a formação das identidades docentes e discentes; (b) questionemos tanto as desigualdade como as diferenças identitárias presentes na sala de aula, buscando compreender e desequilibrar as relações de poder nelas envolvidas; (c) estimulemos a reflexão coletiva, propiciando a formação de grupos de discussão e de aprendizagem nas escolas, por meio dos quais os professores apóiem e sustentem os esforços de crescimento uns dos outros, bem como articulações entre diferentes escolas, entre as escolas e a universidade, entre as escolas e distintos grupos da comunidade. A idéia é que o professor reflexivo preserve a preocupação com os aspectos políticos, sociais e culturais em que se insere sua prática, leve em conta todos os silêncios e todas as discriminações que se manifestam na sala de aula, bem como amplie o espaço de discussão de sua atuação. Tais cuidados, a meu ver, podem evitar que se reduza a prática do professor reflexivo a aspectos técnicos e 
operacionais, dificultando, então, seu emprego em propostas mais conservadoras.

Se em estudo anterior (MOREIRA, 1995), buscando compensar o que me pareceu a supervalorização do político na concepção de intelectual transformador de GIROUX (1988), insisti na importância da dimensão acadêmica do professor reflexivo, defendo hoje que se explicite claramente o caráter político da prática reflexiva, se examinem as relações de poder nela envolvidas e se busque entender como tem sido usada para tornar os professores instrumentalmente úteis para determinados fins. Se não há práticas pedagógicas inerentemente libertadoras ou inerentemente repressivas, e se qualquer prática é cooptável ou capaz de funcionar como fonte de resistência, há que se estabelecer como permanente tarefa política o questionamento das relações de dominação que se corporifiquem na prática do professor reflexivo (GORE, 1994).

\section{Finalizando}

Defender o ponto de vista de que o professor precisa assumir-se como intelectual, a despeito das condições adversas em que trabalha e do desprestígio social associado ao seu exercício profissional, implica demandar que se combinem, em sua formação e em sua prática, dimensões de ordem política, cultural e acadêmica. Implica argumentar que tais dimensões, ainda que não exclusivamente, podem ajudar a conformar identidades docentes críticas e questionadoras dos princípios, dos resultados e do caráter supostamente inevitável do modelo neoliberal e, ao mesmo tempo, mais propensas a aderir a uma prática multiculturalmente orientada, que se contraponha às tentativas homogeneizadoras dos currículos nacionais que se vêm propondo em diferentes países.

É esse professor, a meu ver, o mais capaz de desenvolver formas alternativas de pedagogia que privilegiem a luta pela inclusão e formular, como propõe VAREJÃ̃ (2000), um novo sentido para a desgastada noção de cidadania, a partir de currículos que acolham as diferenças identitárias que marcam os indivíduos e os grupos sociais e, ao mesmo tempo, constituam espaços em que se ensinem e aprendam os conhecimentos e as habilidades necessárias à transformação das relações de poder que socialmente produzem e preservam tais diferenças. É esse professor e são esses currículos que se fa- 
zem indispensáveis nas escolas e salas de aula das sociedades multiculturais contemporâneas, tão marcadas pelos efeitos letais do neoliberalismo e de um processo de globalização excludente, evidentes no estado de angústia, desespero, desesperança, ódio, medo e violência que prevalece em todos os grupos cujas vozes vêm sendo silenciadas e cujos direitos vêm sendo flagrantemente desrespeitados.

\section{REFERÊNCIAS}

ALVAREZ MÉNDEZ, J. M. Tendencias actuales en el desarrollo curricular en España. Educación y Sociedad, n. 6, p. 77-105, 1990.

APPLE, M. W. Power, meaning and identity: critical sociology of education in the United States. British Journal of Sociology of Education, v. 17, n. 2, p. 125-144, 1996.

ARONOWITZ, S.; GIROUX, H. Postmodern education: politics, culture \& social criticism. Oxford, Minneapolis: University of Minnesota Press, 1991.

BOURDIEU, P. Contre-feux. Paris: Liber Raison d'Agir, 1998a.

BOURDIEU, P. A máquina infernal. Folha de São Paulo, 12 jul. 1998b, Caderno Mais, p. 7.

CANEN, A.; MOREIRA, A. F. Reflexões sobre o multiculturalismo na escola e na formação docente. In: REUNIÃO ANUAL DA ANPEd, 22., 1999, Caxambu. Anais... Caxambu: [s.n.], 1999.

GIROUX, H. A. Teachers as intellectuals: toward a critical pedagogy of learning. Massachusetts: Bering \& Garvey, 1988.

GORE, J. M. Foucault e educação: fascinantes desafios. In: SILVA, T. T. (Org.) O sujeito da educação: estudos foucaultianos. Petrópolis: Vozes, 1994.

MOREIRA, A. F. O currículo como política cultural e a formação docente. In SILVA, T. T.; MOREIRA, A . F. (Org.) Territórios contestados: o currículo e os novos mapas políticos e culturais. Petrópolis: Vozes, 1995.

MOREIRA, A . F. As contribuições e os impasses da teoria curricular crítica. In: CHASSOT, A.; OLIVEIRA, R. J. (Org.) Ciência, ética e cultura na educação. São Leopoldo: Unisinos, 1998. 
POPKEWITZ, T. S. The denial of change in the process of change: systems of ideas and the construction of national evaluations. Texto preparado para $\mathrm{o}$ Ministério da Cultura e da Educação da Noruega, Nyvågen, 1995 (mimeog.).

SAID, E. W. Representaciones del intelectual. Barcelona: Paidós, 1996.

SARLO, B. Escenas de la vida posmoderna: intelectuales, artes y videocultura en la Argentina. Buenos Aires: Ariel, 1999.

SCHÖN, D. The reflective practitioner. New York: Basic Books, 1982.

SILVA, T. T. Identidades terminais: as transformações na política da pedagogia e na pedagogia da política. Petrópolis: Vozes, 1996.

SILVA, T. T. Documentos de identidade: uma introdução às teorias do currículo. Belo Horizonte: Autêntica, 1999.

VAREJÃO, F. O. A. Vozes em conflito na construção do conhecimento em sala de aula de Língua Materna. Rio de Janeiro, 2000. Dissertação (Mestrado) - Faculdade de Letras da UFRJ.

YOUNG, R. Liberalism, postmodernism, critical theory and politics. In: SMITH, R.; WEXLER, P. (Ed.) After postmodernism: education, politics and identity. London: Falmer Press, 1995.

ZEICHNER, K. M. A formação reflexiva de professores: idéias e práticas. Lisboa: Educa, 1993. 